Оригинальные статьи / Original articles

https://doi.org/10.18619/2072-9146-2020-4-32-36 уДК 635.132:631.531:581.48

Бухаров А.Ф. ${ }^{1}$, Балеев Д.Н. ${ }^{2}$, Фефелов Ф.О.' ${ }^{1}$ Еремина Н.А.

'Всероссийский научно-исследовательский институт овощеводства - филиал Федерального государственного бюджетного научного учреждения «Федеральный научный центр овощеводства» (ВНИИО - филиал ФГБНУ ФНЦО)

Россия, Московская область,

Раменский район, д. Верея, стр. 500

E-mail: afb56@mail.ru

${ }^{2}$ Всероссийский научно-исследовательский институт лекарственных и ароматических растений

Конфликт интересов: Авторы заявляют об отсутствии конфликта интересов.

Для цитирования: Бухаров А.Ф., Балеев Д.Н. Фефелов Ф.О., Еремина Н.А.

Морфометрические параметры разнокачественности семян моркови и факторы, их определяющие. Овощи России. 2020;(4):32-36.

https://doi.org/10.18619/2072-9146-2020-4-32-36

Поступила в редакцию: 06.04.2020

Принята к печати: 04.05.2020

Опубликована: 25.08.2020

Aleksandr F. Bukharov' ${ }^{1}$

Dmitry N. Baleev ${ }^{2}$, Fedor O. Fefelov', Nadezhda A. Eremina'

All-Russian Scientific Research Institute of Vegetable Growing - Branch of the FSBSI Federal Scientific Vegetable Center 500 , Vereya, Ramensky district,

Moscow region, Russia

E-mail: afb56@mail.ru

${ }^{2}$ All-Russian Scientific Research Institute of Medicinal and Aromatic Plants

Conflict of interest: The authors declare no conflict of interest.

For citation: Bukharov A.F., Baleev D.N., Fefelov F.O., Eremina N.A. Morphometric parameters of carrot seed quality and factors determining them Vegetable crops of Russia. 2020;(4):32-36. (In Russ.) https://doi.org/10.18619/2072-9146-20203-4-32-36

Received: 06.04.2020

Accepted for publication: 04.05 .2020

Accepted: 25.08 .2020
Морфометрические

параметры

разнокачественности семян
моркови и факторы,
их определяющие

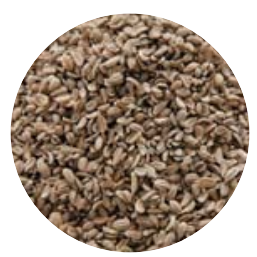

РЕЗЮМЕ

Актуальность. Изучен вклад сортового и экологического факторов в изменчивость длины эндосперма и зародыша семян моркови.

Материал и методы. Объектами для изучения служили оригинальные семена сортов Рогнеда, Любава и Черноземочка, Шантенэ 2461 и Боярыня. Семена выращены на Воронежской и Западно-Сибирской опытных станциях. Измерение линейных размеров семени и эндосперма осуществляли штангенциркулем. Длину зародыша измеряли с помощью микроскопа (Микромед) и видеоокуляра (DCM 300 MD) при х40 увеличении. Статистическую обработку данных исследований двухфакторного опыта проводили с помощью дисперсионного анализа. Различия сравниваемых параметров считали статистически значимыми при $P \quad 0,05$.

Результаты. Линейные размеры всех основных элементов семян, а также индекс Іэ/з в среднем за три года существенно отличались у изученных сортов моркови $(P<0,001)$.

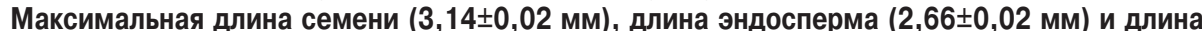
зародыша $(1,23 \pm 0,03$ мм) в среднем за три года отмечена у сорта Рогнеда. Средние значения коэффициента вариации (V) длины семени были минимальными и изменялись от $10,1 \%$ до 12,9\%. Средние значения коэффициента вариации (V) для длины эндосперма изменялись в более широких пределах от 12,0\% до 14,6\%. Длина зародыша имела максимальный уровень вариабельности от $18,7 \%$ у сорта Рогнеда до $20,3 \%$ у сорта Черноземочка 21,3\%. Фактор сорта оказывал преобладающее влияние (от 50,8\% до $86,5 \%$ ) на размер семени и его морфологические элементы. Вклад фактора экологических условий года репродукции в формирование морфометрических параметров не превышал 22,3\%. Это позволило сделать вывод о перспективности отбора и возможности селекционного изменения морфологических параметров семени, которые определяют технологические, посевные и другие их свойства.

Ключевые слова: морковь, экология, сорт, семя, эндосперм, зародыш.

\section{Morphometric parameters of carrot seed quality and factors determining them}

\section{ABSTRACT}

Relevance. The contribution of varietal and environmental factors to the variability of the length of the endosperm and the embryo of carrot seeds was studied.

Materials and methods. The objects of study were the original seeds of Rogneda, Lubava and Chernozemochka, Chantene 2461 and Boyarynya varieties. The seeds were grown at the Voronezh and West Siberian experimental stations. The linear dimensions of the seed and endosperm were measured using a caliper. The length of the embryo was measured using a microscope (Micromed) and a video eyepiece (DCM 300 MD) at x40 magnification. Statistical processing of the research data two-factor experiment was carried out using analysis of variance. Differences in the compared parameters were considered statistically significant at $p$ 0.05 .

Results. The linear dimensions of all the main elements of seeds, as well as the index of le $/ \mathbf{z}$ on average for three years significantly differed in the studied carrot varieties $(P<0.001)$. The maximum length of the seed $(3.14 \pm 0.02 \mathrm{~mm})$, the length of the endosperm $(2.66 \pm 0.02 \mathrm{~mm})$ and the length of the embryo $(1.23 \pm 0.03 \mathrm{~mm})$ on average for three years was observed in the Rogneda variety. The average coefficient of variation $(\mathbf{V})$ of seed length was minimal and varied from $10.1 \%$ to $12.9 \%$. The average values of the coefficient of variation (V) for the length of the endosperm varied in a wider range from $12.0 \%$ to $14.6 \%$. The length of the embryo had a maximum level of variability from $18.7 \%$ in the Rogneda variety to $20.3 \%$ in the Chernozemochka variety $\mathbf{2 1 . 3} \%$. The variety factor had a predominant influence (from $50.8 \%$ to $86.5 \%$ ) on the size of the seed and its morphological elements. The contribution of the environmental conditions of the year of reproduction to the formation of morphometric parameters did not exceed $22.3 \%$. This allowed us to draw a conclusion about the prospects of selection and the possibility of selective changes in the morphological parameters of the seed.

Keywords: carrot, ecology, variety, seed, endosperm, germ. 


\section{Введение}

ак и большинство представителей семейства зонтич-

ных, морковь характеризуется высокой степенью проявления неоднородности семян по окраске, удельной массе степени зрелости, посевным качествам и другим показателям $[1,2]$

Период цветения моркови, как и у других овощных зонтичных культур, обычно растянутый, и семена формируются на побегах, находящихся на разных стадиях развития. Это приводит к образованию разнокачественных семян, в том числе и по морфометрическим параметрам. Характерный для овощных зонтичных культур матрикальный гетероморфизм семян обусловлен, в первую очередь, растянутым периодом созревания семян, как в соцветиях, так и в пределах растения в целом [1, 2]. Многочисленные исследования показали что качество семян моркови уменьшается по мере увеличения порядка ветвления, а в пределах зонтика по направлению от периферии к центру [3, 4, 5, 6, 7, 8, 9]. Аналогичные тенденции характерны для пастернака [10, 4], укропа [11], сельдерея [12].

Кроме того, отмечено, что семена овощных зонтичных культур, собранные с зонтиков разных порядков, могут иметь разные физиологические показатели качества в зависимости от условий проращивания [12, 6, 13]. Это может приводить к возникновению индуцированного покоя [14], изменению долговечности [15] и аллелопатической активности семян $[16,17]$

На качество семян овощных зонтичных культур суще ственное влияние оказывают погодные, климатические, почвенные условия, а также агротехника выращивания, на основании чего разработан экологический принцип подбора оптимальных зон размещения семеноводческих посевов [18]. Поэтому семена для настоящих исследований выращивали в Алтайском крае и Воронежской области, условия которых наиболее благоприятны для семеноводства моркоВи

Важнейшим внутренним фактором, влияющим на качество семян моркови, является недоразвитие зародыша которое обуславливает продолжительность периода гетеротрофного развития проростка [9], физиологические свойства семян в процессе прорастания [19], всхожесть, энергию, долговечность, а также реакцию семян на изменение условий прорастания [20]. Морфологические параметрь представляют интерес для расширения представлений о качестве семян моркови при выращивании, сортировке, хранении, в процессе предпосевной обработки семян [6]

Общепризнано, что морфометрические параметрь семян, как и другие биологические признаки, наследуемы и зависят от видовых и сортовых особенностей $[7,21,8,22]$. Ранее выполненные исследования свидетельствуют, что степень изменчивости морфометрических параметров семян овощных зонтичных культур и норма их реакции, по-видимому, также наследственно обусловлены [23].

Цель настоящей работы - изучить вариабельность линейных размеров зародыша, эндосперма, семени пяти сортов моркови различных лет и места репродукции и определить в системе двухфакторного опыта степень влияния сортового и экологического факторов на эти параметры.

Методика исследования

Исследования выполнены во Всероссийском научноисследовательском институте овощеводства - филиал Федерального государственного бюджетного научного учреждения «Федеральный научный центр овощеводства». Объектами служили оригинальные семена пяти сортов моркови репродукции Воронежской и Западно-Сибирской опытных станций.

Сорт Шантенэ 2461 обладает высокой адаптивной способностью. Вегетационный период 110-120 дней Отличается хорошей лёжкостью. Урожайность - 6-9кг/м². Форма корнеплода коническая. Длина корнеплода - 11-16 см, а масса - 110-250 г. Содержание сухого вещества - о $11,7 \%$ до $13,7 \%$, общего сахара - от 6,0 до 8,9\%, каротина от 9,6 до 14,8 мг\%. Накопление нитратов очень низкое - 19 48 мг/кг. Сорт Боярыня имеет вегетационный период 115 120 дней. Корнеплод цилиндрический с тупым кончиком, длиной 13-17 см, диаметром 3-5 см, массой 170-250 г. Содержание каротина - 11-15 мг\%, сахара - 12-13\% Корнеплоды хорошо хранятся, пригодны для потребления в свежем виде и для переработки.

Сорт Рогнеда среднеспелый, вегетационный период 100-105 суток. Корнеплоды массой 90-160 г с гладкой поверхностью, форма цилиндрическая со слабым сбегом к закругленному концу. Мякоть и сердцевина ярко-оранжевые.
Консистенция мякоти нежная и сочная. Вкусовая оценка - 45 баллов. Сорт обладает относительной устойчивостью к черной гнили и высокой лёжкостью.

Сорт Любава среднеспелый, вегетационный период 95-106 дней. Корнеплод конический со слабым сбегом к основанию с тупым кончиком, иногда заостренный. Длина корнеплода - от 9,4 см до 13,6 см, диаметр - от 3,7 до 4,6см. Головка плоская и слабовогнутая. Форма плечиков плоская или округлая. Окраска коры и сердцевины интенсивно оранжевая. Сердцевина средней величины, круглая и округлоугловатая. Поверхность корнеплода гладкая.

Сорт Черноземочка среднепоздний, с корнеплодом цилиндрической формы с тупым кончиком. Корнеплод средней величины - от 14,5 до 21 см, диаметр - от 3 до 4,5 см. Головка корнеплода ровная слабовогнутая. Форма плечиков плоская. Относительно уровня почвы корнеплод выступает в слабой и средней степени. Сердцевина среднего размера темно-оранжевой окраски.

Преобладающие почвы Западно-Сибирской овощной опытной - черноземы выщелоченные и обыкновенные. Климат региона резко континентальный. Количество часов солнечного сияния равно 1900. Годовой приход ФАР - 55 ккал/см². Безморозный период в среднем составляет 120 дней. Среднегодовое количество осадков - 477 мм. Вегетационный период 2015 года характеризовался ранней тёплой весной и жарким, умеренно влажным летом. Во второй половине вегетации стояла жаркая погода, что положительно сказалось на росте и развитии растений. В 2016 и 2017 годах лето было жарким и влажным, а в августе и сентябре отмечен недостаток осадков при повышенной температуре. Это снизило товарность корнеплодов.

Почвы Воронежской овощной опытной станции представлены мощными выщелоченными (гумуса до 6,4\%) черноземами. Климат региона континентальный. Сумма среднесуточных температур воздуха выше $10^{\circ} \mathrm{C}$ равна 2000-2250 , а выше $15^{\circ} \mathrm{C}$ - $1450-1650^{\circ}$. Среднегодовое количество осадков - 503 мм. Метеорологические условия 2015 года были относительно благоприятны для роста и развития растений моркови. Однако засуха в мае отрицательно отразилась на всходах моркови. Погода в июне - июле была теплой и влажной, что вызвало развитие грибных и бактериальных болезней. Сентябрь выдался теплый и сухой благоприятный для уборки. Метеорологические условия 2016 года были менее благоприятны для моркови. Засуха в сентябре не дала благоприятно развиваться корнеплодам. Отмечено массовое развитие бактериальных болезней. Условия 2017 и 2018 годов были крайне неблагоприятны вследствие засухи, сопровождаемой суховеями, что снизило урожайность и качество семян.

Семена, предназначенные для анализа, предварительно замачивали в 14\% водном растворе гипохлорита натрия в течение 1 часа, после чего скальпелем вычленяли эндосперм и зародыш. Измерение длины семени и эндосперма проводили с использованием штангенциркуля (ГОСТ 166-89). Длину зародыша определяли с использованием микроскопа Микромед (Микромед, Китай) и видеоокуляра DCM 300 MD (Microscope Digital, Китай) при увеличении Ч40, с помощью программы Scope Photo (Image Software V. 3.1.386). Измеряли последовательно длину семени, эндосперма и зародыша. Рассчитывали соотношение длины зародыша к длине эндосперма (IЗ/Э). Повторность опыта трехкратная, в каждой повторности не менее 20 семян. Для полученных средних значений рассчитывали стандартную ошибку среднего. Двухфакторный дисперсионный анализ использовался для проверки значимости основных эффектов (сортовой и экологический фактор) и их взаимодействий на морфометрические параметры семян. Различия в каждой паре сравниваемых значений считали статистически значимыми при Р 0,05

\section{Результаты и обсуждение}

У пяти сортов моркови линейные размеры всех основных элементов семян, выращенных в условиях Алтайского края и Воронежской области, изменялись в значительных пределах

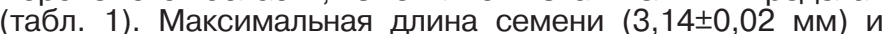

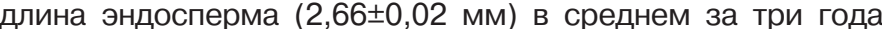
отмечена у сорта Рогнеда. Однако в условиях 2015 года максимальная длина семени и эндосперма отмечена у сорта Любава.

Аналогичная, но более ярко выраженная тенденция изменчивости по годам в пределах изученных сортов была характерна и для длины зародыша. Различия в значениях параметров существенно увеличивались в ряду семя - эндосперм - зародыш. 
Таблица 1. Линейные размеры морфологических элементов семени моркови в зависимости от сорта, года и места репродукции, мм (2015-2018 годы)

Table 1. Linear sizes of morphological elements of carrot seed depending on variety, year and place of reproduction, mm (2015-2018)

\begin{tabular}{|c|c|c|c|c|}
\hline Сорт & Год репродукции & Длина семени & Длина эндосперма & Длина зародыша \\
\hline \multicolumn{5}{|c|}{ Воронеж } \\
\hline \multirow{4}{*}{ Черноземочка } & 2015 & $3,03 \pm 0,05$ & $2,18 \pm 0,03$ & $0,98 \pm 0,02$ \\
\hline & 2016 & $2,95 \pm 0,04$ & $2,54 \pm 0,04$ & $0,98 \pm 0,02$ \\
\hline & 2017 & $3,06 \pm 0,05$ & $2,50 \pm 0,04$ & $0,85 \pm 0,02$ \\
\hline & 2018 & $2,87 \pm 0,06$ & $2,41 \pm 0,05$ & $0,84 \pm 0,02$ \\
\hline \multirow{4}{*}{ Любава } & 2015 & $3,23 \pm 0,04$ & $2,70 \pm 0,03$ & $1,05 \pm 0,03$ \\
\hline & 2016 & $3,16 \pm 0,04$ & $2,67 \pm 0,04$ & $1,12 \pm 0,03$ \\
\hline & 2017 & $3,08 \pm 0,04$ & $2,55 \pm 0,04$ & $1,11 \pm 0,02$ \\
\hline & 2018 & $2,97 \pm 0,04$ & $2,52 \pm 0,04$ & $0,98 \pm 0,02$ \\
\hline \multirow{4}{*}{ Рогнеда } & 2015 & $2,90 \pm 0,04$ & $2,43 \pm 0,03$ & $1,23 \pm 0,03$ \\
\hline & 2016 & $3,18 \pm 0,05$ & $2,82 \pm 0,05$ & $1,32 \pm 0,03$ \\
\hline & 2017 & $3,17 \pm 0,04$ & $2,56 \pm 0,04$ & $1,24 \pm 0,03$ \\
\hline & 2018 & $3,28 \pm 0,04$ & $2,82 \pm 0,04$ & $1,12 \pm 0,02$ \\
\hline \multicolumn{5}{|c|}{ Различия между вариантами существенны при $P<0,01$} \\
\hline \multicolumn{5}{|c|}{ Барнаул } \\
\hline \multirow{3}{*}{ Боярыня } & 2015 & $2,54 \pm 0,03$ & $2,31 \pm 0,03$ & $0,78 \pm 0,02$ \\
\hline & 2016 & $2,59 \pm 0,02$ & $2,34 \pm 0,02$ & $0,85 \pm 0,02$ \\
\hline & 2017 & $2,94 \pm 0,03$ & $2,77 \pm 0,03$ & $0,84 \pm 0,02$ \\
\hline \multirow{3}{*}{ Шантенэ 2461} & 2015 & $2,85 \pm 0,03$ & $2,62 \pm 0,03$ & $1,01 \pm 0,02$ \\
\hline & 2016 & $2,90 \pm 0,03$ & $2,68 \pm 0,03$ & $1,09 \pm 0,03$ \\
\hline & 2017 & $3,16 \pm 0,04$ & $2,70 \pm 0,04$ & $1,07 \pm 0,03$ \\
\hline
\end{tabular}

Различия между вариантами существенны при $P<0,05$

Таблица 2. Значение индекса Із/э для морфологических элементов семян моркови в зависимости от сорта и года репродукции (2015-2018 годы)

Table 2. The value of the embryo length index for the morphological elements of carrot seeds, depending on the variety and year of reproduction (2015-2018)

\begin{tabular}{|l|l|l|l|l|}
\hline \multicolumn{1}{|c|}{ Сорт } & $\mathbf{2 0 1 5}$ & $\mathbf{2 0 1 6}$ & $\mathbf{2 0 1 7}$ & $\mathbf{2 0 1 8}$ \\
\hline Черноземочка & $0,44 \pm 0,09$ & $0,39 \pm 0,01$ & $0,35 \pm 0,01$ \\
\hline Любава & $0,39 \pm 0,01$ & $0,42 \pm 0,09$ & $0,34 \pm 0,08$ & $0,39 \pm 0,01$ \\
\hline Рогнеда & $0,51 \pm 0,01$ & $0,47 \pm 0,01$ & $0,44 \pm 0,07$ & $0,40 \pm 0,07$ \\
\hline Боярыня & $0,34 \pm 0,07$ & $0,36 \pm 0,06$ & 0,05 & - \\
\hline Шантенэ 2461 & $0,39 \pm 0,07$ & $0,41 \pm 0,11$ & $0,31 \pm 0,06$ & - \\
\hline
\end{tabular}

Два сорта моркови, выращенные в условиях Алтайского края, существенно различались по длине семян $(P<0,001)$. Так сорт Боярыня по этому параметру (2,54-2,94 мм) существенно уступал сорту Шантанэ 2461 (2,85-3,16 мм). Длина эндосперма сорта Боярыня в среднем за годы исследований была меньше на 0,20 мм $(P<0,001)$ по сравнению с сортом Шантанэ 2461. Средняя длина зародыша у сорта Боярыня составляла 0,82 мм, а в семенах сорта Шантанэ 2461 - 1,06 MM.

Значение индекса Іэ/з, характеризующего относительную длину зародыша, изменялось от 0,34 $\pm 0,008$ у сорта

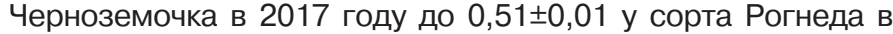
2015 году. Сорт Рогнеда стабильно превышал по этому показателю сорта Черноземочка и Любава, и только в 2018 году это преимущество было не существенным (табл. 2).

Средние значения коэффициента вариации (V) для длины семени были минимальными и изменялись от 10,1\% у сорта Любава до 12,9\% у сорта Черноземочка (рис. 1). Коэффициент вариации этого показателя с учетом года репродукции изменялся в более широких пределах от 8,4\% до 15,0\%. Сорт Рогнеда стабильно занимал промежуточное положение по степени вариабельности длины семени Средние значения коэффициента вариации (V) для длинь эндосперма изменялись в более широких пределах от 12,0\% у сорта Любава до 14,6\% у сорта Черноземочка. Максимальное значение $C_{v}=16,1$ отмечено у сорта Черноземочка. Длина зародыша имела максимальный уро- вень вариабельности. Средние значения коэффициента вариации изменялись в пределах от $18,7 \%$ у сорта Рогнеда до 20,3\% у сорта Черноземочка 21,3\%. В 2015-2016 годах максимальный коэффициент вариации длины зародыша $(20,7-21,2$ \%) отмечен у сорта Любава, а в 2017 и 2018 годах у сорта Черноземочка (21,3\%). Коэффициент вариации длины семян у сортов Боярыня и Шантанэ колебался в пределах 13,5-13,9\% в зависимости от сорта и года исследований. Коэффициент вариации длины эндосперма сортов изменялся в пределах от 13,8 до 14,2\%, а длины зародыша -в пределах 18,8-20,5 \% (рис. 1).

Средние значения коэффициента вариации (V) для относительной длины зародыша Іэ/з изменялись в еще более широких пределах от 19,0\% у сорта Любава до 22,5\% у сорта Черноземочка. Как и по другим параметрам, сорт Рогнеда показал промежуточное значение вариабельности индекса Іэ/3.

Корреляционный анализ свидетельствует, что достаточно тесная связь существует только между линейными размерами семени и эндосперма (табл. 3). Развитие зародыша, повидимому, происходит независимо от эндосперма и семени в целом. Мы неоднократно на разных зонтичных культурах его отмечали $[16,17]$. Определенная автономность развития зародыша, по-видимому, объясняется тем, что это зачаток нового организма, проявляющий таким образом самостоятельность и определенную независимость от материнского растения. 
Коэффициент вариации (V) морфологических элементов семян моркови в зависимости от сорта и года репродукции, \% (2015-2018)

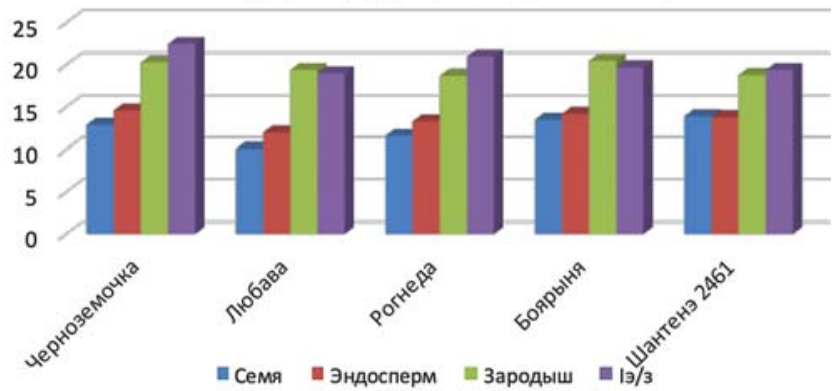

Рис. 1. Коэффициент вариации (V) морфологических элементов семян моркови в зависимости от сорта и года репродукции, \% (2015-2018 годы)

Fig. 1. The coefficient of variation (V) of the morphological elements of carrot seeds, depending on the variety and year of reproduction, \% (2015-2018) ным и составил 58 и 48\% для длины семени и эндосперма, соответственно. На длину зародыша основное влияние оказывал фактор сорта 91\% $(P<0,001)$. На соотношение длины зародыша к длине эндосперма в значительной степени, также, как и в случае с длиной зародыша, влиял фактор сорта $(P=0,006)$, доля влияния которого составила $75 \%$. Таким образом, фактор сорта оказывает существенное влияние на длину зародыша, а на длину семени и эндосперма его влияние снижается и увеличивается влияние экологического фактора.

Следовательно, морфологические структурные элементь семени, как и любые другие признаки, имеют реальную возможность селекционного совершенствования. Семена, если они не представляли хозяйственного интереса, редко подвергались целенаправленному искусственному отбору, хотя потребность в изменении некоторых морфологических физиологических и биохимических признаков семян явно ощущается.

Следует отметить, что в процессе окультуривания многие виды растений, даже не подвергаясь направленной селекции, испытывали давление естественного отбора под влиянием условий выращивания, уборки, обмолота, сортировки,

Таблица 3. Коэффициент корреляции Пирсона (r) морфологических элементов семян моркови в зависимости от сорта (2015-2018 годы) Table 3. The Pearson correlation coefficient ( $r$ ) of morphological elements of carrot seeds depending on the variety (2015-2018)

\begin{tabular}{|l|l|l|l|}
\hline \multicolumn{1}{|c|}{ Сорт } & Семя / Эндосперм & Семя / Зародыш & Эндосперм / Зародыш \\
\hline Черноземочка & $0,736(P<0,001)$ & $0,285(P<0,001)$ & $0,216(P<0,001)$ \\
\hline Любава & $0,790(P<0,001)$ & $0,367(P<0,001)$ & $0,369(P<0,001)$ \\
\hline Рогнеда & $0,836(P<0,001)$ & $0,213(P<0,001)$ & $0,241(P<0,001)$ \\
\hline Боярыня & $0,894(P<0,001)$ & $0,149(P<0,001)$ & $0,001)$ \\
\hline Шантенэ 2461 & $0,812(P<0,001)$ & $0,217(P<0,001)$ & $0,194(P<0,001)$ \\
\hline
\end{tabular}

Коэффициенты корреляции между индексом /э/3 и морфометрическими параметрами имеют отрицательное значение.

Анализ результатов двухфакторного опыта показал, что фактор сорта оказывает существенное влияние на длину семени при $P \leq 0,05$, длину эндосперма и зародыша при $P \leq$ 0,001. Экологический фактор оказывает существенное влияние на эндосперм и зародыш при $P \leq 0,001$. Взаимодействие экологического и наследственного факторов оказывает существенное влияние на длину семени при $P \leq 0,05$ и длину эндосперма при $P \leq 0,001$ (рис. 2).

Вклад фактора сорта в изменчивость длины семени составляет 50,8\%. Эффект экологического фактора не превышает 4,7\%. Взаимодействие этих двух факторов обеспечивает 33,7\% вариабельности длины семени. Изменчивость длины эндосперма (58,5\%) обусловлена фактором сорта, на 22,3\% - фактором года репродукции и только на 15,2\% - их взаимодействием.

Максимальное влияние на размер зародыша (86,5\%) также оказывал фактор сорта. Фактор экологических условий года репродукции обеспечивал только 10,9\% изменчивости этого параметра.

На индекс $I_{\ni / 3}$ максимальное влияние $(66,9 \%)$ оказывал фактор сорта, 20,4\% изменчивости контролируется условиями репродукции, 11,6\% разнообразия обусловлено взаимодействием главных факторов.

Таким образом, фактор сорта оказывал существенное и преобладающее влияние (от 50,8\% до 86,5\%) на размер семени и его морфологические элементы. Вклад экологических условий года репродукции в формирование морфометрических параметров не превышал 22,3\%.

\section{Обсуждение}

Данные, полученные в пределах настоящего опыта, свидетельствуют, что значительная часть изменчивости морфометрических параметров семян моркови наследственно обусловлена. Эффект фактора сорта оказался существен-

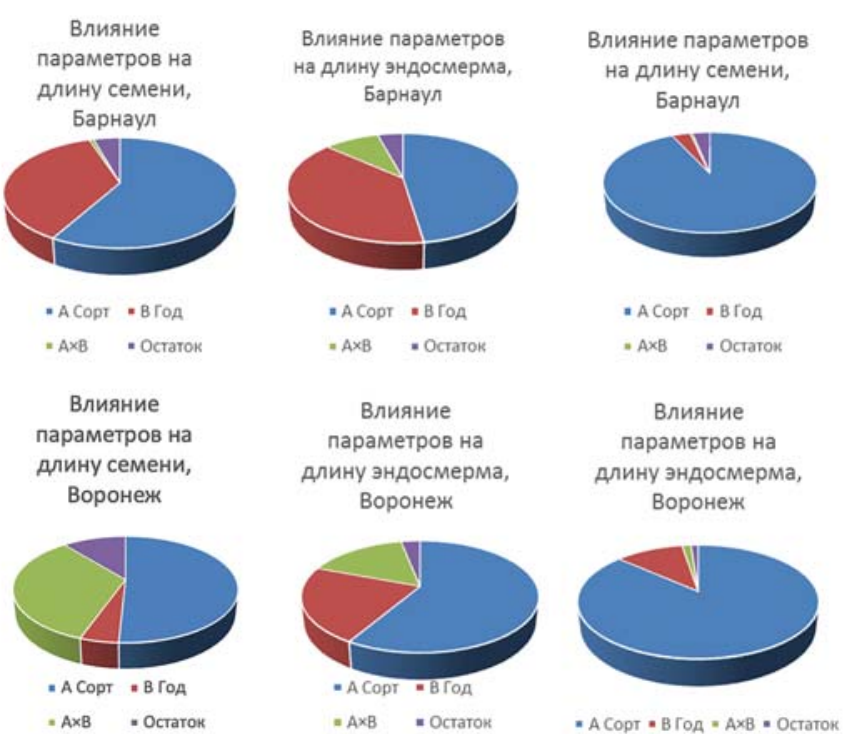

Рис. 2. Вклад факторов сорт (А), год (В), взаимодействие (АхВ) в формирование морфометрических параметров длина семени, длина эндосперма и длина зародыша моркови столовой в условиях Воронежской области и Алтайского края, \% (2015-2018 годы)

Fig. 2. Contribution of factors sort $(A)$, year $(B)$, interaction $(A x$ $B)$ in the formation of morphometric parameters, seed length, endosperm length and length of the carrot germ in the Voronezh region and Altai Territory, \% (2015-2018) 
хранения семян отличных от дикой среды. По-видимому, независимо от человека культивируемые сорта частично утрачивали такие признаки, как ломкость колоса, осыпаемость семян, длительный период покоя. Поэтому целенаправленный искусственный отбор, направленный на изменение морфологических параметров семян следует рассматривать как перспективное направление селекции.

Очевидно, что для характеристики качества семян в практике семеноводства и семеноведения наиболее важным параметром является размер зародыша. Достаточно высокий коэффициент вариации размера зародыша указывает на определенный запас изменчивости признака, который можно реализовать в процессе селекции

Важную роль в системе морфометрических параметров отводят показателю $I_{3 / 3}$. Этот индекс, характеризующий длину зародыша относительно эндосперма, одновремен но указывает и на степень недоразвития зародыша [23]. Ранее была разработана шестибальная шкала градации этого показателя [24]. Проведенные нами исследования показывают, что зародыши в семенах сорта Боярыня в соответствии с данной классификацией можно отнести к 3 классу, а в семенах сорта Шантанэ 2461 - к 4 классу (более крупному относительно эндосперма). Коэффициенты корреляции, рассчитанные между основными морфологическими элементами семени, показали достаточно тесную связь между семенем и эндоспермом и относительную независимость зародыша от этих параметров. Это позволяет предположить независимое наследование и распределение в расщепляющихся популяциях по размеру эндо-

\section{Об авторах:}

Бухаров Александр Федорович - доктор с.-х. наук, главный научный сотрудник группы семеноведения, https://orcid.org/0000-0003-1910-5390

Балеев Дмитрий Николаевич - кандидат с.-х. наук, ведущий научный сотрудник

Фефелов Фёдор Олегович - кандидат с.-х. наук, ст. научный сотрудник Еремина Надежда Александровна - мл. научный сотрудник

\section{- Литература / References}

1. Bianco V.V., Damato G., Defilippis R. Umbel position on the mother plant "seed" yield and quality of seven cultivars of Florence fennel. Act Horticulturae. 1994;(362):51-58. (doi.org/10.17660/actahortic.1994.362.5).

2. Бухаров А.Ф., Балеев Д.Н. Морфология разнокачественности семян овощных зонтичных культур, обусловленная местом формирования на материнском растении. Овощи России. 2012;(2):44-47. [Bukharov A.F. Baleev D.N. Morphology of different quality of seeds of vegetable umbrella crops, due to the place of formation on the mother plant. Vegetable crops of Russia. 2012;(2):44-47.

3. Thompson J.N. Variation among individual seed masses in Lomatium gray (Umbelliferae) under controlled conditions: magnitude and partitioning of the variance. Ecology. 1984;(65):626-631 (doi.org/10.2307/1941425).

4. Gray D. Steckel J.R.A. Parsnip (Pastinaca sativa) seed production: effects of seed crop plant density, seed position on the mother plant, harvest date and method, and seed grading on embryo and seed size and seedling performance. Annals of Applied Biology. 1985;(107):559-570. (doi.org/10.1111/j.1744-7348.1985.tb03172.x).

5. Szafiroska A.I. The correlation between mother plant architecture, seed quality and field emergence of carrot. Acta Horticulturae. 1994;(354):93-98. (doi.org/10.17660/actahortic.1994.354.10)

6. Corbineau F., Picard M.A., Bonnet A., Come D. Effects of production factors on germination responses of carrot seeds to temperature and oxygen. Seed Science Research. 1995;(5):129-135 (doi.org/10.1017/s0960258500002749).

7. Geritz S.A., Kisdi H.E., Meszena G., Metz J.A.J. Evolutionarily singula strategies and the adaptive growth and branching of the evolutionary tree. Evol. Ecol. 1998;(12):35-57. (doi.org/10.1023/a:1006554906681).

8. Galloway L.F., Etterson J.R., McGlothlin J.W. Contribution of direct and maternal genetic effects to life history evolution. New Phytologist 2009;(183):826-838. (doi.org/10.1111/j.1469-8137.2009.02939.x).

9. Panayotov N. Heterogeneity of carrot seeds depending on their position on the mother plant. Folia Horticulturae. 2010;(22):25-30. (doi.org/10.2478/fhort2013-0147).

10. Hendrix S.D. Variation in seed weight and its effects on germination in Pastinaca sativa L. (Umbelliferae). American Journal of Botany. 1984:(71):795-802. (doi.org/10.1002/j.1537-2197.1984.tb14144.x).

11. Holubowicz R., Morozowska M. Effect of umbel position on dill (Anethum graveolens L.) plants growing in field stands on selected seed stalk features Folia Horticulturae. 2011;(23):157-163. (doi.org/10.2478/v10245-011-0024-3)

12. Thomas T.H., Gray D., Biddington N.L. The influence of the position of the seed on the mother plant on seed and seedling performance. Acta Horticulturae. 1978;(83):57-66. (doi.org/10.17660/actahortic.1978.83.7).

13. Dyer A.R., Brown C.S., Espeland E.K. The role of adaptive transgenerational plasticity in biological invasions of plants. Evol. Appl. 2010;(3):179-192. (doi.org/10.1111/j.1752-4571.2010.00118.x).

14. Бухаров А.Ф., Балеев Д.Н. Возникновение индуцированного покоя у семян овощных зонтичных культур под действием аллелопатически сперма и другим признакам, что может значительно упростить отбор.

\section{Заключение}

Разнокачественность семян является негативным фактором в агрономической практике, поскольку может приводить к неоднородности по скорости прорастания, доли проросших семян, изреженности, разному развитию растений. Частично решить проблему разнокачественности семян можно с помощью агротехники и сортировки, но, для изменения морфометрических параметров необходимо использовать селекционные методы. Выявлено, что явление недоразвития зародыша, характерное для семян моркови проявляется у изученных copтов в разной степени, а длина зародыша по сравнению с другими элементами семени варьирует сильнее и в большей степени зависит от влияния наследственного фактора, чем от условий года. Это позволяет предположить возможность селекционного изменения линейных, а также относительных размеров морфологических элементов семени. Низкие значения коэффициента корреляции между размером зародыша с одной стороны и длиной эндосперма и семени с другой свидетельствуют о независимом наследовании этих параметров, следовательно, о перспективности секционного изменения морфометрических параметров семян моркови. Полученные данные позволяют сделать вывод о целесообразности дальнейшего развития генетико-статистических исследований в семеноведении.

\section{About the authors:}

Aleksandr F. Bukharov - Doc. Sci. (Agriculture)

https://orcid.org/0000-0003-1910-5390

Dmitry N. Baleev - Cand. Sci. (Agriculture),

Leading Researcher

Fedor O. Fefelov - Cand. Sci. (Agriculture),

Senior Researcher

Nadezhda A. Eremina - Junior Researcher

активных веществ. Сельскохозяйственная биология. 2016:51(5):714 721. [Bukharov A.F., Baleev D.N. The occurrence of induced rest in the seeds of vegetable umbrella crops under the action of allelopatically active substances. Agricultural biology. 2016;51(5):714-721.]

15. Балеев Д.Н., Бухаров А.Ф. Долговечность семян овощных зонтичных культур и физиология их прорастания. Вестник Алтайского государст венного аграрного университета. 2013;11(109):22-25. [Baleev D.N. Bukharov A.F. Longevity of vegetable umbrella crops seeds and their germination physiology. Bulletin of the Altai state agrarian University. 2013;11(109):22-25.]

16. Бухаров А.Ф., Балеев Д.Н. Анализ влияния факторов, определяющих развитие признака аллелопатической активности семян овощных сельдерейных культур. Вестник Воронежского государственного аграрного университета. 2011;3(30):22-24. [Bukharov A.F., Baleev D.N. Analysis of the influence of factors determining the development of allelopathic activity of vegetable celery seeds. Bulletin of the Voronezh state agrarian University. 2011;3(30):22-24.]

17. Балеев Д.Н., Бухаров А.Ф. Аллелопатия овощных зонтичных (Umberliferae): торможение прорастания и индукция состояния покоя семян. Saarbrucken, Germany. 2012. 112 с. [Baleev D.N., Bukharov A.F. Allelopathy of vegetable Umbelliferae: inhibition of germination and induction of seed dormancy. Saarbrucken, Germany. 2012. 112 p.]

18. Макрушин H.M., Макрушина Е.М., Шабанов Р.Ю., Есоян Е.А. Черемуха Б.М. Семеноводство (методология, теория, практика). Симферополь: ИТ «Ариал». 2012. 556 с. [Makrushin N.M., Makrushina E.M., Shabanov R.Yu, Yesoyan E.A., Cheremukha B.M. Seed pProduction (methodology, theory, practice). Simferopol: it "Ariala". 2012. 556 p.]

19. Tongshun W., Hongling W., Lei W., Baoping S. Germination of heteromorphic seeds of Atriplex aucheri and its hormonal explanation Vegetos - An International Journal of Plant Research. 2014;(27):103-107. (doi:10.5958/j.2229-4473.27.1.017).

20. Vandelook F., Janssens S.B., Probert R.J. Relative embryo length as an adaptation to habitat and life cycle in Apiaceae. New Phytologist. 2012;(195):479-487. (doi.org/10.1111/j.1469-8137.2012.04172.x).

21. Uller T. Developmental plasticity and the evolution of parental effects Trends Ecol. Evol. 2008;(23):432-438. (doi.org/10.1016/j.tree.2008.04.005). 22. Wolf J.B., Wade M.J. What are maternal effects (and what are they not)? Philosophical transactions of the Royal Society of London. Series B. 2009;(364):1107-1115. (doi.org/10.1098/rstb.2008.0238).

23. Бухаров А.Ф., Балеев Д.Н., Иванова М.И. Морфометрия разнокаче ственности семян овощных зонтичных культур в процессе формирования и прорастания. Вестник Алтайского государственного аграрного универсumema. 2014:7(117):26-32. [Bukharov A. F., Baleev D.N., Ivanova M.I. Morphometry of different quality of seeds of vegetable umbrella crops in the process of formation and germination. Bulletin of the Altai state agrarian University. 2014;7(117):26-32.]

24. Necajeva J., levinsh G. Seed dormancy and germination of an endangered coastal plant Eryngium maritimum (Apiaceae). Estonian Journal of Ecology. 2013;(62):150-161. (doi.org/10.3176/eco.2013.2.06). 